\title{
FANDUBBING EM PORTUGAL UM ESTUDO DE CASO SOBRE CULTURA PARTICIPATIVA EM REDE
}

\section{FANDUBBING IN PORTUGAL A CASE STUDY ON ONLINE PARTICIPATORY CULTURE}

\author{
Tiago Vidal \\ Instituto Universitário de Lisboa (ISCTE-IUL), Av. das Forças Armadas, 1649-026 Lisboa, Portugal. \\ Email: tiagovidal1991@hotmail.com \\ Jorge Vieira \\ Departamento de Sociologia e Centro de Investigação e Estudos de Sociologia (CIES-IUL) do Instituto \\ Universitário de Lisboa (ISCTE-IUL), Av. das Forças Armadas, 1649-026 Lisboa, Portugal. \\ Email: jorge_vieira@iscte-iul.pt
}

\begin{abstract}
Resumo: Os fãs de conteúdos mediáticos tendem a ser utilizados recorrentemente como exemplo da cultura participativa online. Com efeito, muitos destes fãs recorrem a ferramentas digitais como forma de expressão, desenvolvendo diferentes práticas tendo os seus objetos de fandom como principal catalisador. Entre estas, o fandubbing é uma prática que carece de atenção académica. Tendo por base uma metodologia qualitativa e os testemunhos de oito elementos pertencentes à comunidade de fandubbers portuguesa, este artigo tenta contribuir com informação aprofundada sobre a atividade em si, os seus praticantes, a relação com o objeto mediático e as plataformas de mediação. Como principais resultados, observámos que os fandubbers entrevistados possuem uma ligação íntima quer com o objeto mediático do qual são fãs, quer com a prática de fandubbing em si. Os utilizadores tendem, através da prática, a apreender uma série de competências, em vários casos de forma autodidata e em contextos informais de aprendizagem. Procuram ainda partilhar as suas produções, de trabalho não remunerado, em plataformas online públicas, como o Youtube, enfrentando subsequentemente adversidades provenientes da apropriação de conteúdos autorais.
\end{abstract}

Palavras-chave: fandubbing, fandom, cultura participativa.

\begin{abstract}
Fans of media content tend to be repeatedly used as an example of participatory online culture. Indeed, many of these fans having their fandom objects as the main catalyst, use digital tools as a form of expression, developing different practices. Among these, fandubbing is a practice that lacks academic attention. Based on a qualitative methodology and the testimonies of eight elements belonging to the Portuguese fandubbers community, this article contributes with in-depth information about the activity itself, its practitioners, the relationship with the media objects and the mediation platforms. Our main results shouw that fandubbers have a deep connection with both their fandom objects and fandubbing itself. Users tend, through practice, to grasp a range of skills, in several cases in a self-taught way and in informal learning contexts. They also seek to share their free labor productions on public online platforms, such as Youtube, coming across difficulties due to the copyrighted nature of the activity.
\end{abstract}

Keywords: fandubbing, fandom, participatory culture. 


\section{Introdução}

São vários os utilizadores das tecnologias de informação e comunicação (TIC) que fazem uso (individualmente ou de forma colaborativa) destas como forma de criar significado(s), partilhando conhecimento e desenvolvendo relações sociais, podendo, em algumas instâncias, formar comunidades em rede sustentadas por afinidades comuns. Entre estes, os fãs de conteúdos mediáticos ao apropriarem-se de diversos conteúdos mediáticos com os quais possuem uma relação e ao transformarem-nos criativamente de acordo com as suas matrizes referenciais pessoais criando fanfics, fanzines (Duffett, 2013), entre outros coprodutos e paratextos (Geraghty, 2015; Gray, 2010) são comumente apontados como exemplo de uma cultura participativa (Jenkins, 1992) em rede.

O fandubbing é uma prática de fãs que partilha algumas destas características. Porém, ao contrário daquelas previamente mencionadas, a informação académica sobre esta atividade é ainda parca, sobretudo no contexto nacional. Reside nesta lacuna o principal motivo que levou ao desenvolvimento desta investigação.

O objetivo primordial foi entender a prática de fandubbing nos seus momentos de produção e partilha online e a relação dos fãs com a prática e com os seus objetos de fandom. Desdobrando em objetivos mais finos:

1) Propostas de definição de fandubbing pelos próprios;

2) Modalidades de relação dos fãs com os textos mediáticos e a prática de fandubbing;

3) Potenciais competências adquiridas;

4) Motivações para a publicação e partilha online de fandubs;

5) Perceção face a trabalho não remunerado e direitos autorais;

\section{Enquadramento teórico: Fandom - definição e contextualização}

Com quase 30 anos de estudos de fãs são várias as formas de equacionar os fãs, dependendo esse olhar do observador e do contexto, podendo este ser mais académico, mediático ou senso-comunal. Se a investigação académica tem tentado, de forma empírica, demonstrar diversidade na abordagem aos fãs, o senso comum ainda tende a adotar uma visão patológica (Jenson, 1992) e estereotipada dos fãs (Booth \& Bennett, 2016).

Fazendo um percurso histórico, o campo académico dos estudos de fãs é, em grande medida, fundado em 1992 pela compilação editada por Lewis (1992) e pela obra de Jenkins (1992), que definia na sua seminal investigação etnográfica os media 
fans como "consumidores que também produzem, leitores que também escrevem, espectadores que também participam" (Jenkins, 1992, p. 208). Nesta ótica, os fãs são vistos como textual poachers participativos e produtivos (Fiske, 1992) que se reapropriam de textos canónicos como matéria prima para novas coproduções, remisturas e paratextos (Geraghty, 2015; Gray, 2010), e não como agentes passivos e recetores acríticos de conteúdos mediáticos ou mesmo como sujeitos desviantes (Jenson, 1992).

Atualmente, são várias as propostas de definição do que é o fandom e a condição de fã, sendo que quase todos os autores sublinham a dificuldade deste exercício conceptual, até porque este não é uma "coisa" que possa ser "capturada" analiticamente (Hills, 2002). Mark Duffet (2013), por exemplo, defende que ao poder ser experienciado de inúmeras formas e através de práticas diversificadas o conceito de fandom é complexo e mutável. Aliás, de acordo com Booth e Kelly (2013, pp. 61-62), mesmo dentro de uma comunidade específica de fãs de um objeto mediático, é possível notar-se diferenças nas formas de viver o fandom, não só de acordo com o contexto online e offline, como em relação ao próprio texto. Fandom significa então coisas diferentes em diferentes contextos que podem, ou não, encontrar-se interligados. Assim sendo, Duffett (2013, p. 19) procura explorar diferentes formas e componentes principais que caraterizam o fandom.

Em primeiro lugar, é imperativo desconstruir o estereótipo de que os fãs são simplesmente consumidores passivos. É claro que alguns destes poderão ser ávidos consumidores de produtos mediáticos, contudo não é exclusivamente a dimensão económica do consumo que define o fandom, mas antes sim todas as dimensões de ligação com o objeto (Duffett, 2013, p. 20). Também devemos compreender que apesar de o fandom poder ser percecionado enquanto um "passatempo", já que ambos se encontram ligados a atividades de lazer, o fandom constitui uma forma de produção e possui uma dimensão de formação identitária (Duffett, 2013, p. 24).

Como tal, podemos definir fandom baseando-o também num processo de identificação (Sullivan, 2013) emocional entre o fã e o seu objeto. Como complemento conceptual, Sandvoss $(2005$, p. 8$)$ define fandom como uma forma de envolvimento emocional e consumo regular de objetos mediáticos diversificados. $\mathrm{Ou}$ seja, conceptualmente trata-se de um relacionamento particular (Grossberg, 1992) estruturado sobretudo por dois vetores: investimento e envolvimento (Busse \& Gray, 2011, p. 426; Sullivan, 2013). De forma mais sistematizada, Mark Duffett $(2013$, p. 2) define o conceito de fandom enquanto o "reconhecimento de uma ligação positiva, pessoal, relativamente profunda e emocional com um elemento mediático da cultura popular". 
Contudo, Sandvoss (2005, p. 6) também considera não ser possível medir a intensidade emocional que um sujeito sente pelo seu objeto, se bem que nas abordagens mais próximas da neurologia (Duarte, Afonso, Jorge, Cayolla, Ferreira \& Castelo-Branco, 2017), psicologia e dos estudos de fãs desportivos, tenha sido já mobilizadas e testadas propostas de escalas para medir a ligação com o objeto e motivações - confira-se por exemplo (Wann, 1995; Wann \& Branscombe, 1993).

O processo de autoidentificação enquanto fã tende a ser do foro íntimo e privado, sendo que certos utilizadores se identificam como fãs apesar de não apresentarem uma ligação emocional forte com o seu objeto, e existem fãs devotos que não se revêm enquanto fãs, devido a este termo ser considerado em alguns contextos como pejorativo. Nesta medida Duffett (2013, p. 25) explica que este processo de identificação não define exclusivamente o que é o fandom, mas constitui a parte pessoal e cultural do conceito, sendo que é necessário que em algum ponto o fã tenha uma relação emocional, ou pelo menos um fascínio, pelo seu objeto mediático de interesse.

Outra possível dimensão constitutiva do conceito de fandom será a sua dimensão performativa (Hills, 2002). Em alguns casos, é possível reconhecer um fã através do vestuário ou das suas formas de conduta. Um exemplo disto é o caso do cosplaying, uma prática onde fãs de diversos textos mediáticos se mascaram de personagens correspondentes a esses textos, desempenhando atividades performativas em eventos de específicos (Lamerichs, 2011). No entanto, resumir o fandom à sua performance pública é assumir que, primeiramente, ela existe, ignorando por completo que alguns fãs podem optar por não expor a sua identidade de fã - veja-se por exemplo o caso específico do desporto onde tal encobrimento do clube do qual se é adepto acontece muitas vezes de forma consciente e estratégica em contextos de jogo (Osborne \& Coombs, 2013). E, segundo, mesmo que alguns fãs procedam à realização de práticas de carater público, muitos deles começam por experienciar ofandom num contexto pessoal e privado (Duffett, 2013, p. 29), como é exemplificado no caso do cosplay.

Em paralelo, podemos também procurar definir o fandom segundo práticas de produtividade (Fiske, 1992) levadas a cabo pelos fãs em torno dos seus objetos de fandom, ou ainda através da partilha e discussão em comunidades de fãs (Jenkins, 1992). São vários os autores que pretendem ir para além de visões dualistas e apontam para várias formas de envolvimento e participação dos fãs, das menos sofisticadas como a distinção entre fãs e seguidores (Tullock \& Jenkins, 1995, p. 23) fãs e aficionados (Jenson, 1992; Shuker, 2001, p. 243), tal como o continuum de Abercrombie e Longhurst (1998) ou Wasco (2001) - tal como mobilizado empiricamente por Jorge (2011). 
O que estas dimensões demonstram é que o conceito de fandom, e por extensão de fã, é utilizado por diversos autores de diferentes formas, não possuindo uma definição precisa (Duffett, 2013, p. 31). Contudo, existem alguns autores (Harrington \& Bielby, 1995; Jenkins, 1995) que procuram definir o conceito de fandom por forma a incorporar todas estas particularidades, sendo que Duffett (2013, p. 31) considera que esta aproximação multidimensional ao fandom é relativamente melhor a reduzi-lo às suas componentes individuais.

\section{Fãs e cultura participativa}

O foco na agência dos utilizadores das TIC (Van Dijck, 2009) e na participação tem sido crescente, chegando-se a falar até de um paradigma da participação no estudo das audiências (Livingstone, 2013). Importa retraçar brevemente a sua origem.

O conceito de cultura participativa, termo cunhado por Henry Jenkins (1992; Jenkins, Purushotma, Weigel, Clinton \& Robison, 2006, p. xi) no seu estudo etnográfico de fãs de conteúdos televisivos, remete para uma "... cultura que diminui barreiras à expressão artística e ao compromisso cívico, mostrando um forte apoio à criação e partilha de conteúdo e um tipo de orientação informal onde participantes mais experientes transpõem conhecimento aos principiantes". Esta definição de Jenkins salienta o importante papel dos indivíduos, destacando a produção de conteúdos de forma individual e/ou colaborativa, a partilha de informação e inclusive a introdução de um sistema informal de instrução onde utilizadores mais experientes tendem a partilhar saberes e competências.

Estas transformações ao nível da sociedade e do papel dos indivíduos também ajudam a salientar a necessidade de modificar determinados conceitos por se encontrarem muitas vezes associados a ambientes industriais, como o de produtores, produção e produto (Bruns \& Schmidt, 2011, p. 3), já que através da utilização de diferentes ferramentas digitais, os utilizadores contribuem continuamente com diversos tipos de criações mediáticas, informação e conhecimentos para este ambiente digital, desempenhando atividades de produção sem se encontrarem ligados a estes contextos corporativos, atuando assim enquanto "produsers" (Bruns, 2008, p. 21).

Vários autores, entre eles Jenkins, Purushotma, Weigel, Clinton e Robinson (2006), Bruns (2008) e Benkler (2006) consideram este quadro de informação em rede e cultura participativa como um espaço mais democrático, onde os utilizadores possuem, até certo ponto, maior poder sobre aquilo que querem desenvolver e partilhar.

Contudo vários autores são críticos desta visão otimista de participação enquadrando-a antes como trabalho não renumerado (Vesnic-Alujevic \& Murru, 
2016) num quadro de uma economia da atenção. Fuchs (2017, p. 25), por exemplo, é bastante cético da visão democratizante destes autores, referindo que esta suposta autonomia é proporcionada por plataformas online desenvolvidas por organizações industriais, como por exemplo a Google e o Youtube. O próprio conceito de Web 2.0, buzzword criada por O'Reilly (2007) como estratégia para a reposição da confiança depois da crise especulativa da bolha dot.com (Fuchs, 2017), consiste num modelo de negócio que vive da cultura participativa. Neste sentido podemos concluir que, num quadro de uma economia da atenção, este tipo participação e de desenvolvimento de bens pelos utilizadores constitui antes uma espécie de exploração (Andrejevic, 2009) e de "free labour" (Bakioglu, 2016; Hesmondhalgh, 2011; Terranova, 2000, p. 35) ou "user-generated labor" destes amadores experts (Baym \& Burnett, 2009). Por exemplo, em ambientes digitais online, os utilizadores comunicam entre si, partilham informação e disponibilizam dados e conteúdos, entre outras práticas, produzindo aquilo que Fuchs (2017) chama de "internet prosumer commodity", que pode ser entendido como um perfil individual onde ficam registadas todas estas atividades que serão analisadas e vendidas a indústrias da publicidade. Segundo o autor, o modelo de negócio online funciona de forma análoga ao da televisão e rádio, ou seja, através de publicidade. Contudo, a grande diferença é que mercadorias compradas vão-se refletir mais tarde em publicidade direcionada para os utilizadores. Este caso é representativo de uma tendência crescente nos media, a cooptação (Das \& Ytre-Arne, 2018; Stehling, Alujevic, Jorge \& Marôpo, 2018), ou seja, o processo pelo qual as indústrias beneficiam do trabalho dos utilizadores e como lucram com estes. No caso do Youtube o valor reside na co-criatividade e nos conteúdos gerados pelos seus utilizadores no quadro de uma cultura participativa em rede (Burgess \& Green, 2009).

Carpentier (2012, p. 175) define o conceito de participação no quadro mais alargado de uma teoria democrática, isto é, segundo o mesmo a participação é definida enquanto um processo político no qual os atores envolvidos nos processos de decisão são enquadrados por relações de poder (até certo ponto) igualitárias. Carpentier distingue dois tipos de participação: a minimalista, que é caracterizada por uma falta de balanço na divisão de poder entre os atores, e a maximalista onde existe um maior equilíbrio de poder entre todos os membros envolvidos. No entanto, dado que o controlo de grande parte das plataformas online pertence a empresas industriais, como é referido por Fuchs (2017), podemos assumir que nos encontramos perante um tipo de participação minimalista.

Outra crítica apontada por Danah Boyd (Jenkins, Ito \& Boyd, 2016) refere como as ferramentas e plataformas digitais promovem uma participação de tipo individualista, o que pode colocar em risco o bem-estar social. Por exemplo, há 
alguns anos o slogan do Youtube era "Do it Yourself", e enfatizava a produção e expressão individual, mas não na necessidade de atenção e visualização das produções e expressões de outros utilizadores (Jenkins, Ito \& Boyd, 2016, p. 26). No mesmo sentido, o próprio ato de construção de uma rede personalizada com base nos interesses pessoais e preocupações acaba por produzir bolhas (Pariser, 2011) e ilhas informacionais de conhecimento (Lovink, 2011) e limitar a aprendizagem e aceitação de outro tipo de ideologias e opiniões (Jenkins, Ito \& Boyd, 2016, p. 28). Verificamos então que apesar de se registar uma diminuição de determinadas barreiras artísticas neste espaço online, emergiram paralelamente novos obstáculos e assimetrias sociais, assim como o aumento de outras já existentes. Ou seja, resfriando a perceção de uma participação ampla e global, percebendo que nem todos seremos realmente produsers (Bird, 2011).

\section{Fandubbing e fansubbing}

O foco desta investigação é a exploração de uma prática de fãs específica, o fandubbing. Contudo, dada a falta de informação académica sobre esta, procurámos explorar uma prática similar - o fansubbing - como forma de encontrar alguns fatores que se ligassem a esta prática, já que, apesar das suas especificidades, partilham de algumas características: ambas consistem numa forma de tradução/adaptação de texto mediático. Se a primeira assenta na tradução e dobragem sonora, o fansubbing fica-se pela tradução textual.

Cintas e Sánchez (2006, p. 37) definem fansub como "uma versão traduzida e legendagem de um programa de anime japonês criada por fãs", podendo esta estender-se a outros tipos de conteúdos como filmes ou dramas televisivos (Pérez-González, 2012, p. 2013).

Este é um fenómeno social online realizado por indivíduos não profissionais e sem preparação formal e considerado "ilegal" (Pérez-González, 2012, p. 2013) já que vive da apropriação e redistribuição de conteúdo autoral não-licenciado, mas regido por molduras éticas particulares (Ito, 2017).

Historicamente, a origem atividade de fansubbing esteve enraizada na dobragem de conteúdos pertencentes a contextos geográficos distantes, neste caso orientais por ocidentais. A exportação da animação japonesa para o mercado ocidental iniciou-se por volta dos anos 60, sendo que as distribuidoras optaram, como forma de adaptação linguística, por dobrar estas séries ao invés de as legendar (Pérez-González, 2009, p. 263). Contudo, dado que o público-alvo ocidental era mais generalizado, social e culturalmente diversificado do que aquele presente na cultura oriental (Pérez-González, 2009, p. 261), várias adaptações foram então feitas aos 
produtos importados resultando na eliminação nos produtos importados de vários elementos de cariz cultural japonesa, transformando-os em produtos sem "odor", ou seja: "culturally odourless products" (Iwabuchi, 2002).

A fim de combater esta problemática, os fãs procuraram legendar diversos produtos de diferentes culturas, introduzido em alguns casos aquilo que é chamado de "Tu Cao", que corresponde a uma série de comentários sócio-culturais inseridos pelos fansubbers nos produtos mediáticos, procurando conectar os fãs aos diferentes contextos e situações que lhes são apresentados (Dwyer, 2016, p. 148).

O fansubbing surge assim como uma resposta a uma série de necessidades que não estão a ser colmatadas por profissionais de tradução, sendo que os fãs reconhecem esta falta de atenção dada ao papel da língua no contexto da cultura participativa, procurando resolver o problema por si próprios (Dwyer, 2016, p. 156). Contudo ao longo do tempo têm ocorrido várias ligações entre plataformas digitais dedicadas ao fansubbing e a indústria de entretenimento (e.g., Viki, Crunchyroll, entre outros), resultando por um lado na legitimação da prática, mas ao mesmo tempo criando debates entre as comunidades de fãs sobre a possibilidade destas conexões irem contra o próprio ethos da prática em si (Dwyer, 2016, p. 146).

É também importante apontar a posição da indústria face a este fenómeno, sendo que no caso da indústria de animação japonesa, esta prática é utilizada como forma de testar o mercado (Jenkins, 2008, p. 150), implicando que estamos perante uma outra situação de free labour.

Existem ligações entre os dois tipos de tradução narrativa: fandubbing e fansubbing. No caso das dobragens, estas foram criticadas fortemente pelos fãs devido às várias adaptações realizadas que pretendiam apaziguar o contexto cultural na qual se inseriam - a tal criação de "culturally odourless products" (Iwabuchi, 2002). No caso das legendagens, estas surgem como resposta a essas modificações textuais procurando elucidar e descrever as várias referências culturais encontradas no objeto mediático.

\section{Metodologia}

Numa investigação de pendor qualitativo é essencial explorar a forma como os participantes percecionam o que os rodeia, ou seja, devemos tentar compreender o mundo e os seus significados segundo a perspetiva intersubjetiva dos indivíduos entrevistados (Bryman, 2012, p. 399). No caso desta investigação intensiva, procurámos, através de entrevistas realizadas a membros da comunidade de fandubbers portuguesa, compreender a prática do fandubbing segundo o olhar e discursos dos seus principais protagonistas - os próprios fandubbers. 
No que concerne aos critérios de seleção de participantes no estudo, a ênfase foi colocada numa inserção efetiva na comunidade, sendo que certos aspetos como antiguidade da prática ou volume de fandubs realizados não foram considerados como fatores determinantes para essa escolha, já que o objetivo do trabalho foi apresentar a prática de fandubbing e os seus praticantes enquanto indivíduos com diferentes, ou semelhantes, perceções em relação à atividade e ao objeto de interesse. Através de uma estratégia de recrutamento em bola de neve, foram convidados enquanto parte de uma amostra não representativa de 8 fandubbers: seis elementos do género masculino e dois do género feminino, entre os 19 e os 26 anos, sendo identificados através da letra $\mathrm{F}$, seguido de um número que corresponde à ordem da realização da entrevista. No que toca ainda à sua caracterização, a maioria referenciou estar a trabalhar, encontrando-se alguns a frequentar graus de ensino, seja superior ou profissional. Ora, quer em contexto profissional ou académico, muitas destas ocupações relacionam-se com multimédia, nomeadamente em contextos digitais online, ou então com teatro e representação, ou seja, domínios e valências pertinentes e capitalizáveis na prática de fandubbing. Os locais de residência estão distribuídos por Portugal continental. Do total, pelo menos três viviam nos arredores de Lisboa, e os restantes encontravam-se em regiões mais a norte de Portugal (por exemplo, Coimbra e Porto). A maioria vive com o agregado familiar.

Em relação às entrevistas, vários autores, entre eles Salmons (2016), referem diversas vantagens na utilização de métodos de inquirição online como forma de obter informação sobre os diferentes significados atribuídos pelos indivíduos à realidade social (Bryman, 2012, p. 399) aliada a uma melhor gestão de recursos. O software Skype foi então considerado uma boa alternativa para o desenvolvimento das entrevistas, pois possibilitou a mediação de encontros através de vídeo com os entrevistados, sendo possível ter em atenção aos contextos e alguns indícios, nomeadamente expressões faciais e mudanças na tonalidade de voz.

Contudo, este tipo de recolha de informação também possui algumas limitações: primeiramente, encontramo-nos dependentes dos recursos tecnológicos dos entrevistados para a realização das entrevistas; segundo, dado que a interação com os entrevistados é mediada e não ocorre em copresença existe uma maior possibilidade de estes poderem ser interrompidos durante as entrevistas (Salmons, 2016), especialmente quando consideramos que em todos os casos analisados, os utilizadores encontravam-se nos seus domicílios, onde situações como interrupções por parte de terceiros, poderiam afetar substancialmente o fluxo discursivo e consequentemente o desenrolar das entrevistas; e finalmente, a dependência de um mediador tecnológico para este tipo de recolha de informação pode ser problemático, dada a possível existência de problemas técnicos (e.g., problemas com o Skype, 
com o computador, entre outros) (Hooley, Marriott \& Wellens, 2012) quer por parte do entrevistador, e/ou do entrevistado, podendo resultar numa interrupção prolongada da entrevista ou em casos mais gravosos, no seu término.

As entrevistas foram desenvolvidas em torno dos objetivos principais da investigação, seguindo um formato semi-estruturado. Primeiramente procurámos explorar, de uma forma generalizada, representações sobre o conceito de fandubbing de acordo com a interpretação pessoal dos entrevistados, propondo questões relacionadas com elementos mais técnicos da prática, como quais os materiais e ferramentas utilizadas, o processo de desenvolvimento e qual o produto final. De seguida explorámos as relações existentes entre os fãs, o seu objeto de fandom e a prática em si, questionando-os sobre os primeiros contactos com a prática e a forma como estes se relacionam com os objetos que são escolhidos para serem transformados. Posteriormente tentámos saber como é que os entrevistados adquiriram as competências necessárias para o desenvolvimento da atividade, inquirindo sobre contextos de aprendizagem. Seguidamente focámo-nos em perceber os motivos por detrás da partilha dos seus produtos e qual a sua perceção face aos comentários feitos aos seus fandubs. Finalmente, os fãs foram questionados sobre a sua posição sobre direitos de autor, e quais as dificuldades em partilharem online os seus conteúdos apropriados.

\section{Resultados}

\section{Como é que os participantes definem o fandubbing?}

Primeiramente, procurou-se identificar a prática em si segundo as representações e definições de fandubbing por parte dos entrevistados. Os fandubbers F1 e F4 definem a atividade como dobragens amadoras, totais ou parciais, de um dado texto mediático (filmes e séries de animação ocidental ou oriental, videojogos, séries de ação, conteúdos online e, em alguns casos, músicas), onde todas, ou parte das personagens, são dobradas por um fã ou vários, e em que cada um desempenha diferentes papéis. É importante notar que o conceito de dobragem, no caso da atividade de fandubbing, não implica forçosamente a adaptação de um texto de uma língua para outra, sendo que de acordo com a fandubber $\mathrm{F} 3$ a escolha do texto para a dobragem surge pelo interesse do fã e não inevitavelmente por particularidades mais técnicas como o idioma, tempo ou género de conteúdo. Apesar de a prática de fandubbing consistir, efetivamente, no ato de dobragem de um determinado texto, na maioria dos casos, o produto final corresponde a um vídeo que junta as gravações feitas pelos fãs, ou seja, o processo de dobragem, com o texto selecionado, resultando naquilo que os fãs designam de fandub (F4). 
É então importante ter em consideração que a elaboração de um fandub implica a apropriação de um texto mediático com o qual o fã detêm uma ligação, mais ou menos, íntima, recorrendo à utilização de várias ferramentas digitais para a obtenção do objeto mediático (F1). Este trabalho não remunerado é realizado de forma amadora e sem apoio, financeiro ou técnico, de estúdios profissionais de dobragens, sendo realizado em contextos amadores e domésticos ou pelo menos, não profissionais (F4) assemelhando-se a outras práticas de fãs descritas por Duffett (2013, pp. 170-171; 186-187) onde se dá a apropriação de objetos mediáticos e a sua transformação criativa por indivíduos, em vários casos, com um perfil amador.

O produto final tende a ser público, sendo partilhado em plataformas sociais online, como por exemplo o Youtube (F4).

F1: “Bem, o fandubbing (...) não é algo que é feito por obrigação, (...) mas sim pelo amor que uma pessoa tem a uma cena determinada, pode ser de um filme, pode ser de uma série, animada ou de imagem real..."

No caso de F1 deve existir uma relação íntima entre este e o seu objeto, que o impulsiona à realização da prática. Por sua vez, F4 refere que fandubbing "é quando uma pessoa, que tem interesse pela área das dobragens, tenta fazer dobragens em casa", valorizando antes o gosto pela atividade como algo determinante para a definição do próprio conceito. Esta separação não implica que exista uma disjunção entre o objeto de fandom e a prática em si, muito pelo contrário, a realização da atividade de fandubbing ocorre, na maioria dos casos, como uma resposta à ligação do fã com o seu objeto de interesse, ou com algum elemento específico deste, sendo que aquilo que vai variar é antes a intensidade dessa relação e os diferentes motivos que levam à criação desse relacionamento. Apesar de o texto funcionar como um catalisador para o desenvolvimento da prática, o fandubber tende também a desenvolver um interesse pela prática em si. Todavia, quando questionados sobre a prática de fandubbing, os fãs entrevistados costumam valorizar um destes interesses, não necessariamente esquecendo o outro, mas valorizando-os de formas diferentes. Assim sendo as relações com os textos e com a atividade em si são dois fatores determinantes na construção da identidade do fandubber.

Relações entre o fandubber, o objeto de fandom e a prática de fandubbing

Posteriormente foi explorado o início desta prática. Como vimos Duffett (2013, p. 2) define inicialmente o conceito de fandom como o reconhecimento de uma ligação profunda e pessoal com um elemento mediático, algo que se reflete no caso dos fandubbers F1 e F5, em que é referida uma ligação com um tipo de produto mediático específico que data às suas infâncias, neste caso, conteúdos cinematográficos da Disney, e que, pelo menos no caso de F5, se manteve até ao presente, refletindo a 
lealdade da fã enquanto consumidora continuada desta marca (Hills, 2002, p. 36). Motivados por esse interesse, os fandubbers realizavam uma série de práticas envolvendo citações vocais, totais ou parciais, dos respetivos textos mediáticos, refletindo o interesse dos fãs pela área de dobragens. Ambos optam por se focar na relação pessoal com os textos, sendo que as atividades desenvolvidas funcionavam como uma espécie de reflexo, ainda que imperfeito (Duffet, 2013, p. 26), dessa relação.

Contudo a ligação entre o fandubber e o seu objeto não tem necessariamente de derivar de um sentimento nostálgico (Bolin, 2016). Por exemplo, F8 refere que o critério para a seleção do produto que irá dobrar deverá ser algo do género comédia, não referindo qualquer texto específico. Por sua vez, F3 explica esta seleção pode ser baseada na identificação com diferentes emoções transmitidas num excerto específico do mesmo, impulsionando-a para a realização da prática, ou seja, a conexão pode ser feita com determinados elementos parcelares. Outra vezes, como é no caso de F6, o interesse recai antes numa personagem específica de um determinado produto mediático. Esta seleção da personagem a dobrar é um elemento importante para a produção de fandubbing, independentemente de constituir, ou não, a principal motivação para o seu desenvolvimento.

F3: [Eu posso selecionar um conteúdo para dobrar] por ser desafiante em termos pessoais. Por exemplo, fazer uma voz completamente diferente da minha. Eu tenho uma voz muito aguda, muito fofa... e fazer desta voz uma coisa mais maléfica e macabra, por exemplo, é desafiante. (...) é porque é um desafio em termos pessoais, [ou então, porque eu] gosto muito daquela personagem ou então porque eu acho que a minha voz se assemelha à da personagem...

F3 refere duas razões que podem contrapor-se quando falamos na seleção de uma personagem para dobrar. Primeiramente, é necessário compreender que um fã pode desenvolver uma ligação íntima com uma personagem particular de um texto o que, consequentemente, pode levar o fandubber a querer interpretar essa personagem. Em contrapartida, a fã também refere a possibilidade de seleção de uma personagem baseando-se apenas na semelhança de voz. Dado que a prática de fandubbing consiste numa dobragem, a adequação da voz é um fator valorizado por vários fandubbers, aliás, alguns deles, em determinadas ocasiões, acabam mesmo por abdicar de dobrar aquilo que gostam (F5).

Compreendemos assim que apesar de existir uma relação entre o fandubber e o seu objeto, existe igualmente uma ligação íntima entre este e a prática em si. F8 explica que teve, desde muito jovem, uma ligação próxima com as dobragens, realizando atividades que envolviam a gravação de falas suas em áudio e de conteúdo mediático em vídeo. De seguida o fã reproduzia os dois conteúdos gravados em 
simultâneo, procurando simular um efeito de dobragem. Neste caso, a ênfase do fã é atribuída à ligação com a parte eminentemente prática e técnica do fandubbing e com o seu desenvolvimento, o que não implica que não exista uma relação com um objeto de interesse, mas antes que o entrevistado optou por focar-se mais na relação empírica com a própria atividade.

Os casos supracitados demonstram a existência de relações com os objetos e a prática que tiveram início num contexto historicamente e tecnologicamente distinto do contemporâneo, caracterizado por uma maior digitalização e comunicação em rede o que possibilita não só um acesso mais diversificado e facilitado a conteúdos, mas também a ferramentas de manipulação digital. É importante compreender que apesar de muitos fandubbers começarem a desenvolver o interesse pelo dobragem desde muito novos, a prática é identificada pelos mesmos como sendo aquela desenvolvida no contexto digital atual, considerando este como determinante para a realização da atividade, não só por causa do acesso a diferentes ferramentas e conteúdos online, como também pela acessibilidade a uma dimensão social caraterizada pela facilitação da comunicação com outros fãs, criação de grupos de interesse e a publicação dos respetivos produtos para um público interessado (F7, F8 \& F4). É neste espaço online que alguns entrevistados entraram em contacto com a prática pela primeira vez. No caso de F4 e F7, foi mediante a exploração e experimentação com diferentes recursos digitais, segundo um tipo de participação messing around (Ito, Horst, Bittanti, Boyd, Herr-Stephenson, Lange, Pascoe \& Robinson, 2008, p. 22), e tendo por base os seus textos de fandom, que os fãs acabaram por "descobrir" a prática, desenvolvendo um interesse posterior por esta.

\section{Aprendizagem e consolidação de competências}

Dado que a prática de fandubbing consiste primariamente numa dobragem, existem várias competências que podem ser desenvolvidas, nomeadamente conhecimentos técnicos de edição de conteúdos audiovisuais, mas também dramatúrgicos ou mesmo gestão de projetos.

São várias as formas de aprendizagem deste tipo de competências, sendo que algumas podem encontrar-se associadas a conhecimentos apreendidos em estabelecimentos de ensino tradicionais, sendo depois transpostos para esta atividade, enquanto que outras podem ser adquiridas de forma informal autodidata. Por exemplo, no caso de $\mathrm{F} 3$ e F4, ambos referem ter conhecimentos teatrais, apreendidos através de formações ou outros meios de aprendizagem mais tradicionais, que consideram úteis para o desenvolvimento e aperfeiçoamento da prática de fandubbing. Contudo, isto não implica que todas as competências são exclusivamente adquiridas em contextos escolares e formais, até porque as mesmas encontram-se dependentes 
dos trajetos educativos de cada fã. Por exemplo, ainda no caso de F3, esta explica que o seu acervo de conhecimento sobre a edição de elementos audiovisuais resultou de uma aprendizagem autodidata informal, sendo que a fandubber procurou tutoriais online. Na descrição de cultura participativa, Jenkins Purushotma, Weigel, Clinton \& Robinson (2006, p. xi) explica como utilizadores mais experientes podem partilhar o seu conhecimento através de um sistema de ensino/aprendizagem informal em rede. Tal reflete-se no caso de F4, que relata que os seus conhecimentos de interpretação e estudo das personagens foram desenvolvidos com a ajuda de membros da comunidade através da Internet. Estas formas de aprendizagem ajudam não só a caracterizar alguns fandubbers enquanto indivíduos autodidatas, capazes de explorar e desenvolver competências diversas, tendo por objetivo complementar os seus interesses pessoais como também a definir a comunidade de fandubbers portuguesa enquanto um espaço em rede sustentado pela construção e partilha de conhecimento entre os diversos pares. As habilidades e competências dos fandubbers são então o resultado de uma junção de saberes, e desenvolvimento posterior, que deriva de diferentes contextos, mais ou menos institucionais, neste caso escolares e/ ou profissionais e em comunidades de interesse informais.

\section{Publicação e partilha de fandubs}

Na definição do conceito de fandubbing, foi referido que este podia ter um caráter público, isto porque na maioria dos casos os fãs procuraram partilhar os seus produtos em plataformas sociais online como, por exemplo, o Youtube. As motivações que levam à publicação dos textos modificados são variadas, mas relacionam-se em grande parte com o interesse pela prática e respetivo objeto de fandom. Por exemplo, F8 justifica a sua partilha como uma forma de exposição social das suas competências enquanto fandubber. Por seu turno, F4 partilha o seu conteúdo como uma forma de expor publicamente, o seu fandom pessoal assim como o texto com que partilha essa relação. A publicação de fandubs acaba então por ser uma forma de exposição, mas também de expressão identitária.

A publicação em plataformas online implica que estes se encontrem expostos a comentários e críticas públicas por parte de utilizadores que são identificados pelos fandubbers como consistindo, na sua maioria, em crianças e jovens-adultos que possuem uma ligação com o texto original que está a ser dobrado (F4), e/ ou que tenham interesse na área de dobragens, encontrando-se entre estes outros fandubbers (F8). Apesar da maioria dos fãs conseguir caraterizar de uma forma generalizada a sua audiência, o desenvolvimento dos fandubs não é habitualmente feito com um público-alvo em mente, sendo que este é mais uma consequência da exposição do produto em si, do que propriamente um objetivo da produção. Contudo, isso não 
implica que os fandubbers não tenham em consideração os comentários destes utilizadores, muito pelo contrário. F2, por exemplo, refere a importância de receber feedback como algo "bom", independentemente de este ser positivo ou negativo, apesar de realçar os comentários favoráveis por lhe transmitirem uma sensação de satisfação pessoal ao saber que os utilizadores gostaram do seu trabalho. Outro tipo de apreciação valorizado pelos fãs consiste no feedback disponibilizado por membros da própria comunidade e que pode funcionar como elemento de aprendizagem a ter em atenção durante o desenvolvimento de futuros projetos. Adicionalmente, a partilha destes conteúdos é também considerada uma mais valia dentro da própria comunidade de fandubbers, já que permite aos diferentes membros ter uma perceção das diversas competências do fã em questão, podendo eventualmente resultar no desenvolvimento de projetos colaborativos e inclusive mesmo na criação de grupos dentro da comunidade, o que acaba por não ir ao encontro à posição de boyd (Jenkins, Ito \& Boyd, 2016) de participação mais individualista nos contextos online. Contudo, a partilha de fandubs nas plataformas digitais acarreta várias implicações para os fandubbers.

\section{Perceção face a trabalho não remunerado e direitos autorais}

Considerando a natureza desta prática de fãs, que envolve a apropriação de conteúdo criado originalmente por outros autores e sua respetiva adaptação sonora para outro idioma, e que o produto final será, na maioria dos casos, publicado em plataformas digitais online de domínio público, os fãs referem as diversas adversidades no que toca à exposição dos seus trabalhos.

F3 : (...) o Youtube tem esta coisa chamada direitos de autor... e é por causa disso que eles bloqueiam vídeos (...) Eu nunca tive um strike [um aviso por parte da plataforma] que levasse o meu canal a ser bloqueado... mas muitos dos meus vídeos foram bloqueados não só em Portugal, como no resto do mundo (...) E isso é uma treta porque (...) para começar, eu não monetizo os meus vídeos (...) e depois, porque sim... a animação pertence à Disney, ou à Dreamworks ou seja quem for e a música pertence a outra pessoa qualquer, mas a voz no vídeo pertence-me!

Primeiramente é importante referir que a plataforma mencionada pelos entrevistados, no que toca ao tópico de direitos de autor, é o Youtube. De acordo com F3, a forma como o sistema de direitos autorais funciona neste espaço resulta muitas vezes no bloqueamento do conteúdo infrator, tornando-o indisponível a nível nacional e/ou internacional, ou, na pior das circunstâncias, na terminação do canal do utilizador. Nenhum dos fandubbers criticou o conceito de direitos de autor em si, 
defendendo que todos deveriam ser capazes de proteger aquilo que lhes pertence (F4 \& F6). Contudo, muitos fãs parecem concordar que as consequências pela utilização de conteúdo não licenciado no Youtube são demasiado severas, alguns, como F3 e F7, chegam mesmo a demonstrar o seu desapontamento pelo facto de não conseguirem partilhar os fandubs que lhes deram tanto trabalho a produzir. Tal como F3, muitos procuram justificar a publicação dos produtos utilizando dois argumentos: primeiro, os fãs não possuem qualquer tipo de lucro com o desenvolvimento da prática (F5 \& F6); segundo, porque apesar de estes reconhecerem que o texto original pertence aos respetivos detentores de direitos autorais, a voz do fã continua integrada no fandub em si, e esta é de exclusiva autoria dos próprios fandubbers.

No entanto, alguns fãs mencionam um outro tipo de "penalidade" aplicada pelo Youtube que, de acordo com estes, é significativamente menos prejudicial que aquelas referidas anteriormente, consistindo na integração de anúncios publicitários nos seus vídeos, implicando que os gestores da plataforma e autores dos textos originais em questão, possam lucrar diretamente e indiretamente com o conteúdo desenvolvido pelos fandubbers. Podemos então argumentar que isto consiste numa forma de cooptação de free labour, como descrito por Terranova (2000, p. 35; 2013), em que as produções dos utilizadores tornam-se numa fonte de rendimento para grandes empresas (Fuchs, 2017). Tal podia ser considerado problemático para os fãs, já que outras entidades iram beneficiar do trabalho aplicado no desenvolvimento destes projetos de fãs. Mas, pelo contrário, a maior parte deles não parece incomodado por esta possibilidade (F6), ou então que a mesma não os afeta de todo (F4), já que os mesmos não rentabilizam a prática, alguns referindo inclusiva que esta não é "popular" o suficiente para ser rentável a qualquer nível (F2), optando por indicar a dificuldade em publicar o seu conteúdo no Youtube como o seu principal problema com a plataforma. Existem alguns, como F3, que referem esta situação de free labour como sendo "psicologicamente problemática", afirmando que é incomodativo que outros estejam a lucrar com a sua voz, mas que se recusa a deixar de produzir conteúdos por causa disso (F3). Por outro lado, existem alguns fãs que concordam, de bom grado, com esta política de direitos de autor, já que os permite "ajudar" os autores dos objetos mediáticos que os fandubbers optam por dobrar e com quem partilham uma ligação. F8 explica que "No que toca a fandubs, eu não creio que haja qualquer problema [com os detentores de direitos autorais integrarem anúncios nos vídeos], porque é uma forma de sustentar... de certa maneira... a companhia que criou aquilo que tu escolheste dobrar" (F8). Esta perceção sobre o assunto coincide com o conceito de Duffett de que “... ser fã significa amar o artista e compreender onde se encontram limites" (2013, p. 110). Apesar de os fandubbers 
possuírem uma ligação profunda com o objeto de fandom que optam por dobrar, estes continuam a reconhecê-lo como pertencendo a outra entidade, procurando mesmo ajudá-la. Relativamente à possibilidade de os gestores da plataforma lucrarem com os fandubs, os fãs menos críticos também parecem não considerar isto problemático, percecionando esta ação como um compromisso justo, dado que estes utilizam o Youtube como forma de publicarem o seu trabalho (F1).

Apesar de podermos argumentar que existe a falta de uma perspetiva mais crítica por parte dos fandubbers face ao conceito de free labour no Youtube, tal parece ocorrer devido ao objetivo de maximização da partilha, o que pode levar a que os fãs ignorarem completamente esta problemática já que a sua preocupação principal relaciona-se com a partilha de conteúdos em si. Contudo, apesar da perceção negativa do Youtube, quer devido às suas restrições face à utilização de material não-licenciado, ou devido à possibilidade de os fãs serem explorados por esta plataforma social, a maioria dos fandubbers afirma que não publicaria os seus conteúdos em outras plataformas se estes só pudessem escolher uma, independentemente de estas serem geridas por utilizadores, semelhante ao Wikipédia, ou não.

F4: "Na minha mente, tem tudo a haver com exposição (...) é um modelo pay-to-win, ou seja, se não pagarmos pela exposição o vídeo não alcançará ninguém [e] infelizmente, o modelo de prática do Youtube funciona desta forma (...)."

Isto significa que mesmo que os fãs tivessem acesso a um website que resolvesse os problemas previamente mencionados, a maioria só consideraria uma mudança de plataforma se esta tivesse o mesmo nível de exposição que o Youtube, dando ainda mais ênfase à importância da partilha dos seus conteúdos a um público interessado, ao ponto de estes aceitarem a possibilidade de serem explorados em troca desta.

\section{Conclusão}

Este artigo teve como intuito conhecer melhor uma prática de fãs pouco estudada, o fandubbing, recorrendo para tal aos discursos de uma amostra não representativa de praticantes e balizada no contexto nacional contemporâneo. Como objetivo central interessava perceber de forma mais fina os formatos de relacionamento dos fandubbers com, por um lado os objetos que escolhem reapropriar e, por outro, com a prática.

Como contributos, no que diz respeito à relação entre os fandubbers e o texto mediático, é importante referir que existem não só diferentes formas de experienciar e viver o fandom individual (Duffett, 2013, pp. 20-30) mas também diferentes elementos com os quais os fãs estabelecem uma relação pessoal. De acordo com a amostra, a relação, de intensidade variável, pode ser motivada pelo gosto e interesse por um dado texto mediático ou apenas por certas personagens ou cenas 
específicas. Alguns fãs referem ter desenvolvido fandubs de produtos com os quais partilham memórias nostálgicas que datam há sua juventude - fase da vida essencial para a produção de nostalgia mediática (Bolin, 2016). Tal remete ainda para a ideia de que os fãs possuem um tipo de relação continuada com o produto e que se pode estender ao longo do tempo biográfico. Contudo, os fãs também admitem estabelecer uma ligação forte com a prática em si, em alguns casos resultando da posterior experimentação com diversas ferramentas digitais, identificando evidencias de um tipo de participação messing arround (Ito, Horst, Bittanti, Boyd, Herr-Stephenson, Lange, Pascoe \& Robinson, 2008). O fandubbing, que apesar de ser inicialmente encarado enquanto um passatempo para alguns, é caraterizado por elementos com os quais o fã sente uma identificação intensa, tornando esta atividade parte da identidade pessoal dos seus praticantes.

De acordo com as representações dos fãs entrevistados, o fandubbing pode ser definido como o processo de dobragem de variados textos mediáticos, com os quais os fãs possuem algum tipo de relação, mais ou menos intensa, através da utilização de diversas ferramentas de edição de objetos multimédia e de captação de áudio, sendo que o produto final, designado de fandub é habitualmente partilhado em diferentes plataformas digitais, tendo sido o Youtube a mais referida.

No que toca às competências, ficámos a saber que estes fãs inquiridos procuraram desenvolver uma série de conhecimentos relacionados com dimensões técnicas como o tratamento de áudio, edição de vídeo, mas também dramatúrgicas como o estudo de personagens, que lhes permitem, segundo os mesmos, desenvolver fandubs de melhor qualidade. Vários fandubbers explicam que muitas destas competências resultam da articulação de conhecimentos adquiridos em contexto escolar com aqueles desenvolvidos através de uma investigação autodidata em contextos informais.

Estas produções são depois publicadas em plataformas sociais online, nomeadamente o Youtube, como uma forma de exposição pública do seu trabalho e das suas identidades, identificando os comentários dos utilizadores, assim como o dos seus pares, como, normalmente, um reforço positivo para o desenvolvimento da prática podendo eventualmente resultar na elaboração de projetos colaborativos.

Quando confrontados com o conceito de direitos de autor face à natureza da prática de fandubbing, os fãs dizem compreender a importância da propriedade intelectual, mas argumentam que as políticas impostas na plataforma do Youtube são demasiado severas, impossibilitando os fandubbers de publicarem o seu conteúdo e que o seu objetivo não é de lucro com a prática, mas antes sim uma disseminação dos textos escolhidos - aumentando assim o seu valor cultural e, como tal económico num quadro de uma economia da atenção. Numa leitura mais crítica, esta atividade, que é dita como frequente, também representa uma forma de free labour (Terranova, 
2000, p. 35) para plataformas que subsistem graças às produções audiovisuais não remuneradas desenvolvidas por utilizadores amadores (Burgess \& Green, 2009).

Em termos de limitações é importante referir que esta análise exploratória reflete somente alguns aspetos característicos do fandubbing e dos seus protagonistas e não todas as suas nuances. Outro ponto a ter em atenção é a falta de representatividade da amostra que poderia ser colmatada com mais participantes no estudo.

No que fica para eventuais agendas de investigação futuras damos pistas para questões de pesquisa adicionais, nomeadamente se as competências adquiridas no desenvolvimento da prática são capitalizáveis noutros contextos, e, se sim, de que forma; e qual a atitude dos fãs face às dobragens profissionais. Metodologicamente seria interessante mobilizar uma estratégia etnográfica, online e offline, no sentido de aprofundar a pesquisa e procurar eventuais segmentações e perfis de fãs.

Como contributo, este tipo de investigação qualitativa de pendor exploratório cumpriu o seu objetivo inicial, tendo disponibilizado várias pistas referentes à prática de fandubbing, nomeadamente a ligação existente entre o fã e o seu objeto, a relação com a prática que é revestida de orgulho identitário e que potencia a aquisição de competências autodidatas em contextos informais não escolares, normalmente mediados pela internet e com uma componente colaborativa.

\section{Notas}

Este artigo consiste numa versão revista, editada e com novas dimensões de análise da dissertação "Representações, identidade e práticas de fãs na cultura participativa: Um estudo de caso sobre fandubbing em Portugal" de Tiago Vidal orientado por Jorge Vieira no ISCTE-IUL.

Por decisão pessoal, os autores do texto escrevem segundo o novo acordo ortográfico.

\section{Referências}

Abercrombie, N., \& Longhurst, B. (1998). Audiences. Londres: Sage.

Andrejevic, M. (2009). Exploiting YouTube: Contradictions of user-generated labor. In P. Snickars, \& P. Vonderau (Eds.), The YouTube reader (2a Ed.) (pp. 406-423). Estocolmo: The National Library of Sweden.

Bakioglu, B. S. (2016). Exposing convergence: YouTube, fan labour, and anxiety of cultural production in 'Lonelygirl15'. Convergence, 24(2), 184-204.

Baym, N. K., \& Burnett, R. (2009). Amateur experts. International Journal of Cultural Studies, 12(5), 433-449.

Benkler, Y. (2006). The wealth of networks: How social production transforms markets and freedom. Haven Connecticut: Yale University Press. 
Bird, E. (2011). Are we all produsers now?. Cultural Studies, 25(4-5), 502-516.

Bolin, G. (2016). Passion and nostalgia in generational media experiences. European Journal of Cultural Studies, 19(3), 250-264.

Booth, P., \& Bennett, L. (2016). Introduction: Seeing fans. In L. Bennett, \& P. Booth (Eds.), Seeing fans: Representations of fandom in media and popular culture (p. 1). Londres: Bloomsbury.

Booth, P., \& Kelly, P. (2013). The changing faces of Doctor Who fandom: New fans, new technologies, old practices?. Participations. Journal of Audience E Reception Studies, 10(1), 56-72.

Bruns, A. (2008). Blogs, Wikipedia, Second Life and beyond: From production to produsage. Nova Iorque: Peter Lang.

Bruns, A., \& Schmidt, J. (2011). Produsage: A closer look at continuing developments. New Review of Hypermedia and Multimedia, 17(1), 3-7.

Bryman, A. (2012). Social research methods. Oxford: Oxford University Press.

Burgess, J., \& Green, J. (2009). YouTube online video and participatory culture. Cambridge: Polity Press.

Busse, K. B., \& Gray, J. (2011). Fan cultures and fan communities in nightingale. In V. Nightingale (Ed.), The handbook of media audiences (pp. 425-443). Londres: Blackwell.

Carpentier, N. (2012). The concept of participation. If they have access and interact, do they really participate?. Fronteiras, 14(2), 164-177.

Cintas, J. D., \& Sanchéz, P. M. (2006). Fansubs: Audiovisual translation in an amateur environment. The Journal of Specialised Translation, (6), 37-52.

Das, R., \& Ytre-Arne, B. (2018). The future of audiences. A foresight analysis of interfaces and engagement. Cham: Palgrave Macmillan.

Duarte, I., Afonso, S., Jorge, H., Cayolla, R., Ferreira, C., \& Castelo-Branco, M. (2017). Tribal love: The neural correlates of passionate engagement in football fans. Social Cognitive and Affective Neuroscience, 12(5), 718-728.

Duffett, M. (2013). Understanding Fandom: An introduction to the study of media fan culture. Nova Iorque: Bloomsbury.

Dwyer, T. (2016). Multilingual publics: Fansubbing global TV. In P. D. Marshall, G. D'Cruz, S. McDonald, \& K. Lee (Eds.), Contemporary publics: Shifting boundaries in new media, technology and culture (pp. 145-162). Londres: Palgrave Macmillan.

Fiske, J. (1992). The cultural economy of fandom. In A. L. Lewis (Ed.), The adoring audience: Fan culture and popular media (pp. 30-49). Londres: Routledge.

Fuchs, C. (2017). Social media: A critical introduction. Londres: Sage.

Geraghty, L. (Ed.) (2015). Popular media cultures. Fans, audiences and paratexts. Hampshire: Palgrave Macmillan.

Gray, J. (2010). Show sold separately: Promos, spoilers, and other media paratexts. Nova Iorque: New York University Press.

Grossberg, L. (1992). Is there a fan in the house? The affective sensibility of fandom. In L. Lewis (Ed.), The adoring audience: Fan culture and popular media (pp. 50-68). Londres: Routledge. 
Harrington, C. L., \& Bielby, R. D. (1995). Soap fans: Pursuing pleasure and making meaning in everyday life. Philadelphia: Temple University Press.

Hesmondhalgh, D. (2011). User-generated content, free labour and the cultural industries. Ephemera. Theory politics in organization, 10(3/4), 267-284.

Hills, M. (2002). Fan cultures. Nova Iorque: Routledge.

Hooley, T., Marriott, J., \& Wellens. J. (2012). What is online research? Using the internet for social science research. Londres: Bloomsbury.

Ito, M. (2017). Ethics of fansubbing in anime's hybrid public culture. In J. Gray, C. Sandvoss, \& C. L. Harrington (Eds.), Fandom: Identities and communities in a mediated world (pp. 333-353). New York: New York University Press.

Ito, M., Horst, H., Bittanti, M., Boyd, D., Herr-Stephenson, B., Lange, P. G., Pascoe, C. J., \& Robinson, L. (2008). Living and learning with new media: Summary of findings from the digital youth project. Chicago, IL: The John D. \& Catherine T. MacArthur Foundation.

Iwabuchi, K. (2002). Recentering globalization: Popular culture and Japanese transnationalism. Durham e Londres: Duke University Press.

Jenkins, H., (1992). Textual poachers: Television fans and participatory culture. Nova Iorque: Routledge.

Jenkins, H. (2008). Convergence culture where old and new media collide. Nova Iorque: New York University Press.

Jenkins, H., Ito, M., \& Boyd, D. (2016). Participatory culture in a networked era. Cambridge, Reino Unido: Polity Press.

Jenkins, H., Purushotma, M., Weigel, K., Clinton, \& Robison, A. (2006). Confronting the challenges of participatory culture. Media education for the $21^{\text {st }}$ century. Cambridge, Massachusetts: MIT Press.

Jenson, J. (1992). Fandom as pathology. The consequences of characterization. In L. Lewis (Ed.), The adoring audience: Fan culture and popular media (pp. 9-26). London: Routledge.

Jorge, A. (2011). Young audiences and fans of celebrities in Portugal. Comunicação $\mathcal{E}$ Cultura, (12), 47-60.

Lamerichs, N. (2011). Stranger than fiction: Fan identity in cosplay. Transformative Work and Cultures, (7).

Lewis, L. (Ed.) (1992). The adoring audience: Fan culture and popular media. Londres: Routledge.

Livingstone, S. (2013). The participation paradigm in audience research. The Communication Review, 16(1-2), 21-30.

Lovink, G. (2011). Networks without a cause: A critique of social media. Cambridge: Polity. O'Reilly, T. (2007). What is web 2.0: Design patterns and business models for the next generation of software. Communications $\mathcal{E}$ Strategies, (1), 17.

Osborne, A., \& Coombs, D. S. (2013). Performative sport fandom: An approach to retheorizing sport fans. Sport in Society, 16(5), 672-681.

Pariser, E. (2011). The filter bubble: What the internet is hiding from you. Londres: Penguin.

Pérez-González, L. (2009). Fansubbing anime: Insights into 'butterfuly effect' of globalisation on audiovisual translation. Perspetives Studies in Translatology, 14(4), 260-277. 
Pérez-González, L. (2012). Co-creational subtitling in the digital media: Transformative and authorial practices. International Journal of Cultural Studies, 16(1), 3-21.

Salmons, J. E. (2016). Doing qualitative research online. Londres: Sage.

Sandvoss, C. (2005). Fans: The mirror of consumption. Cambridge, Reino Unido: Polity Press.

Shuker, R. (2001). Understanding popular music. Londres: Routledge.

Sullivan, J. (2013). Media fandom and audience subcultures. In B. Gunter, \& D. Machin (Eds.), Media audiences (pp. 189-212). Londres: Sage.

Stehling, M., Alujevic, L. V., Jorge, A., \& Marôpo, L. (2018). The co-option of audience data and user-generated content: Empowerment and exploitation amidst algorithms, produsage and crowdsourcing. In R. Das, \& B. Ytre-Arne (Eds.), The future of audiences (pp. 79-99). Cham, Suiça: Palgrave Macmillan.

Terranova, T. (2000). Free labor: Producing culture for the digital economy. Social Text, 18(2), 33-57.

Terranova, T. (2013). Free labour. In T. Scholz (Ed.), Digital labor. The internet as playground and factory (pp. 33-57). New York and London: Routledge.

Tullock, J., \& Jenkins, H. (1995). Science fiction audiences: Watching Doctor Who and Star Trek. Londres: Routledge.

Van Dijck, J. (2009). Users like you? Theorizing agency in user-generated content. Media, Culture E Society, 31(1), 41-58.

Vesnic-Alujevic, L., \& Murru M. F. (2016). 'Digital audiences' disempowerment: Participation or free labour', Participations. Journal of Audience $\mathcal{E}$ Reception Studies 13(1), 422-430.

Wann, D. L. (1995). 'Preliminary validation of the sport fan motivation scale', Journal of Sport Social Issues 19(4), 377-396.

Wann, D. L., \& Branscombe, N. R. (1993). Sports fans: Measuring degree of identification with their team. International Journal of Sport Psychology, 24(1), 1-17.

Wasko, J., (2001), Understanding Disney: The Manufacture of fantasy. Cambridge: Polity.

Data de submissão: 14/09/2018 | Data de aceitação: 14/11/2018 